\title{
Oncological-Surgical Treatment in Inoperable and Border Operable Nonmicrocellular Lung Cancer
}

\begin{abstract}
Introduction: Approximately only $20-40 \%$ of those who suffer from nonmicrocellular lung cancer at detection of disease are candidates for operational treatment. Pre-operational use of inductive oncological therapy at $60-75 \%$ of cases "takes" the disease into lower level, while at $50 \%$ of cases it is possible to do resectional treatment. The aim of work is to demonstrate efficiency of inductive oncological treatment in relation to possibility of resection.

Material and methods: This analysis includes 62 patients who underwent different surgical treatment, and after inductive oncological treatment.

Results: There is a ignificant statistical difference in frequency of appearance between the two most common sorts of cancer $\left(x^{2}=25 ; p=0\right)$, the same as statistically significant difference in frequency of certain sorts of cancer according to gender $(p=$ 0). Using Fisher exact test, there was no statistically defined significant dependence between the sort of cancer and its sensitivity to chemotherapy $(p=0,2)$ the same as there was not statistical dependency of chemo therapeutical sensitivity in relation to gender $(p=1)$. Using chi-square test, there was no defined statistically significant difference in frequency of sort of operation in relation to sort of cancer $\left(x^{2}=1 ; p=0,6\right)$. There is a presence of statistically significant positive connection between the days spent at intensive care and days spent at the ward of surgically treated patients (rho $=0,63 ; p<0,01$ ) and also there is statistically significant dependence between the response to chemo therapy and days spent at intensive care $(p=0)$. There is also defined statistically significant dependency between the sort of operational treatment and days spent at intensive care and at ward of standard care $\left(X^{2}=17 ; p=0\right.$ vs. $X^{2}=11$; $\mathrm{p}=0)$.

Conclusion: There is an evident relation of sort of surgical treatment and operational techniques to duration of post operational treatment.
\end{abstract}

\section{KEY WORDS:}

lung cancer, inductive oncological therapy, sort of surgical treatment.

DOI: $10.7251 / S M D 1401010 H$

(Scr Med 2014:45:10-13)
Ademir Hadžismailović ${ }^{1}$ Kemal Grbićc ${ }^{1}$ Alen Pilav ${ }^{1}$, Alma Alihodžić-Pašalić ${ }^{1}$, Vlado Lovre ${ }^{2}$

${ }^{1}$ Clinic for Thoracal Surgery, $\mathrm{KCU}$ in Sarajevo, Sarajevo, Bosnia and Herzegovina ${ }^{2}$ Clinic for Lung Diseases Podhrastovi, KCU in Sarajevo, Sarajevo, Bosnia and Herzegovina

\section{Contact address:}

Ademir Hadžismailović Clinic of thoracic Surgery University Clinical Center Sarajevo Bolnička 25, 710oo Sarajevo, BiH Tel: 033 297 238, 061159889 e-mail: ademihadzismailović@ hotmail.com

Submitted: February 23, 2014 Accepted: April 7, 2014.

\section{Introduction}

The most important part of therapy treatment of nonmicrocellular lung cancer is resectional treatment, whose aim is maximum survival and eventual cure with less morbidity and perioerational morbidity as well as perseverance of life quality. During the operation, radical and totally curative resection is done, when the primary tumor is completely removed with lymph denectomy of regional lymph nodes, with macroscopically visible tumoral infiltrations as well as when it is confirmed that resectional borders are without presence of malignity. ${ }^{1-3}$ 
Polymorfity and untypical of symptomatology of disease, as well as its long time period of development result in detection of disease in already developed phase, when there is metastatic disimination, malign invasion of contra lateral lymph nodes, and local affection of intra thoracal structures. All the above mentioned makes surgical treatment contra indicative. According to numerous studies, only $20-40 \%$ of patients, after being diagnosed with malign of lung are candidates for surgical treatment. ${ }^{1,4,5}$

In the last 20 years, they have started with the application of inductive (neoadjuvant) oncological therapy, with the aim to improve the survival through "taking" the disease into lower level, influencing primary tumor, drainage lymph nodes, notentially present micro metastasis, as well as other substances originating from the primary tumor.

It was evident that, with the abovementioned therapy, the disease led to a lowerlevel at $60-75 \%$ of patient, and at initially evaluated inoperable cases, resection was possible, after inductional therapy at $50 \%$ of patients. A great number of studies on the large number of samples has confirmed significantly longer survival of combined modality of curing, even three times higher, in relation to oncological treatment on its own. ${ }^{6-9}$

It is commonly spread attitude that, during radiographical and bronchiological preoperational reevaluation of disease, surgical treatment is justified only at clear regression on the level of primary tumor and mediistinuum and that it is justified to do the least possible volume of resection, as long as ex tempore test of operational material confirms healthy resectional borders. Taking into account secondary effect of inductive therapy, we have to find maximally qualitative surgical access bearing in mind decreasing number of post operational complications. ${ }^{8,10,11}$

The aim of work is to define efficiency of inductive therapy at initially inoperable and border operable nonmicrocellular lung cancer, to reevaluate regression of change in size, and to demonstrate the efficiency of oncological treatment in relation of possibility with resection, post operational treatment, statistical dependency of mentioned parameters, and frequency of early post operational complications in relation to type of surgical treatment.

\section{Patients and Methods}

This analysis included 62 patients of different age group and both genders, who underwent the surgical treatment at Thoracic Surgery Clinic KCU in Sarajevo during the period from January 1st, 2011 to December 31st, 2013 after going through 2-6 phases of inductive oncological therapy because of inoperable or border operable nonmicrocellular lung cancer and according to the decision of interdisciplinary consillium for tumors. Different therape- utical modalities were applied with cisplatin as base therapy.

Bronchio pulmological diagnostical analysis of patients was done at Lung Disease Clinic KCU in Sarajevo, and was minimally consisted of CT of thorax with intravent application of contrast means, bronchoscopy and spirometric tests, sonography of stomach, before and after the oncological treatment. Pathohistological diagnosis was defined according to standard histological types of tumor, at the Institute for Clinical Pathology KCU in Sarajevo, and samples of tumors were taken by endoluminal biopsy during bronchoscopy, with radiographically led transthoracic needle biopsy or by thoracoscopical treatment.

In our analysis initial size of tumor was taken according to radiographical test before the therapy (CT), as well as according to post operational pathohistological test. Resectional treatments were done according to standard posteroletar thoracotomic access with separate anesthesia. Vascular elements were resecinated by vascular selfstitchings or by double ligation, while the bronchial structures were always done by lineral staples with or without preserving of resected bronchus by transpositioned shank of intercostal muscle. Duration of hospital postoperational treatment was divided in number of days being cured at section of intensive care or at the word, while evident complications were only those which appeared before resigning the patients.

The results are presented descriptively, numericaly, with tables and graphs with legends and descriptive explanation of some values and variables. Findings are observed in absolute and the percentage values, calculating the arithmetic means and standard deviation. Nonparametric variables were analyzed using chi-square test. Statistical significance $(\alpha)$ is set as $\mathrm{p}<0,05$.

\section{Results}

Frequency of surgically treated patients according to gender and age structure with standard statistic parameters is demonstrated in Table 1.

Table 1. Demonstration of analyzed patients according to gender and age structures

\begin{tabular}{llll}
\hline Descriptive statistics & Male & Female & Total \\
\hline Frequency (f/N) & 48 & 14 & 62 \\
\hline Arithmetic mean (AS) & 63,1 & 59,9 & 61,9 \\
\hline Standard mistake AS & 0,3 & 0,4 & 0,3 \\
\hline Standard deviation (SD) & 0,9 & 2,6 & 0,9 \\
\hline Minimum (years) & 49 & 39 & 39 \\
\hline Maximum (years) & 77 & 69 & 77 \\
\hline
\end{tabular}


There was a statistically significant difference in average values of age of patients with lung cancer in relation to their gender $(p=0)$. From the above mentioned it is evident that it is more frequent in males and this relation is $3: 1$.

Frequency of planocellular lung cancer at male was $80,4 \%$ (39/48), adenocancer - 15,2\% (7/48), and macrocellular cancer - 4,4\% (2/48). Relation between planocellular and adenocancer at females was identical - 50\% (7/14), and there is no macrocellular lung cancer.

Statistically there was a significant difference in frequency of appearance between two most common types of lung cancer at total number of patients $\left(\chi^{2}\right.$ test $\left.=25 ; p=0\right)$. Fisher exact test showed that there was certified statistically significant difference in frequency of certain types of lung cancer according to gender $(\mathrm{p}=0)$.

Average size of cancer before chemotherapy was $78 \pm 3$ $\mathrm{mm}$, and is statistically bigger than after the therapy $51 \pm 3 \mathrm{~mm}(\mathrm{p}<0,05)$. Average size of regression is $27 \pm$ 2 millimeters. Ficher exact test did not show statistically significant dependency between type of cancer and its sensitivity to chemotherapy $(p=0,2)$ the same as there was no statistical dependency of chemotherapeutic sensitivity in relation to gender $(\mathrm{p}=1)$.

When compared to the surgical treatments, the leading ones were pulmectomies with preservation of bronchi $-34 \%$ (21/62), standard pulmectomies $-31 \%(19 / 62)$, lobectomies and bilobectomies-27\% (17/62), andeksplorative thoracotomies $-8 \%(5 / 62)$

Chi-square test did not certify statistically significant difference in frequency of sort of operation in relation to type of cancer $\left(\mathrm{X}^{2}=1 ; \mathrm{p}=0,6\right)$.

Average number of days spent at the intensive care was 6,8 $\pm 0,4$, and average number of days spent at the hospital ward was $8,5 \pm 0,6$. There was a defined statistically significant positive connection between days spent at the intensive care and days spent at the hospital ward at surgically treated patients because of lung cancer (rho $=0,63 ; \mathrm{p}<0,01)$.

Significant statistical connection between gender, type of cancer and days spent at the intensive care was not found. Fisher exact test certified statistically significant dependency between response to chemotherapy and days spent at the intensive care $(\mathrm{p}=0,03)$.

There was no notable significant dependency between gender, type of cancer, impact of chemotherapy and days spent at the ward.

Tables 2. and 3. show a relationship between number of post operational days spent at the intensive care and the ward in dependency of type of surgical treatment in percentage and in numerals.

Table 2. Dependency of sort of surgical treatment and days spent at the intensive care

\begin{tabular}{|c|c|c|c|c|}
\hline \multirow{2}{*}{$\begin{array}{l}\text { Sorg of } \\
\text { surgical } \\
\text { treatment }\end{array}$} & \multirow{2}{*}{ Relation (N) } & \multicolumn{2}{|c|}{$\begin{array}{l}\text { Days of intensive } \\
\text { care (DIC) }\end{array}$} & \multirow{2}{*}{ Total } \\
\hline & & $\begin{array}{l}\text { Less } \\
\text { than } 7\end{array}$ & $\begin{array}{l}\text { More } \\
\text { than } 7\end{array}$ & \\
\hline \multirow{4}{*}{ Pulmoctomy } & $\mathrm{N}$ & 5 & 14 & 19 \\
\hline & Sort of surgical tr. & 26,3 & 73,7 & 100 \\
\hline & $\overline{\mathrm{DIC}}$ & 16,2 & 53,8 & 33,3 \\
\hline & Total & 8,7 & 24,6 & 33,3 \\
\hline \multirow{5}{*}{$\begin{array}{l}\text { Pulmoctomy } \\
\text { with } \\
\text { preservation } \\
\text { of bronchus }\end{array}$} & $\mathrm{N}$ & 10 & 11 & 21 \\
\hline & Sort of surgical tr. & 47,7 & 52,4 & 100 \\
\hline & $\overline{\mathrm{DIC}}$ & 32,3 & 42,3 & 36,8 \\
\hline & Total & 17,6 & 19,3 & 36,8 \\
\hline & $\mathrm{N}$ & 16 & 1 & 17 \\
\hline \multirow{3}{*}{$\begin{array}{l}\text { Lobectomy } \\
\text { Bilobectomy }\end{array}$} & Sort of surgical tr. & 94,1 & 5,9 & 100 \\
\hline & $\overline{\mathrm{DIC}}$ & 51,6 & 3,9 & 29,8 \\
\hline & Total & 28,0 & 1,8 & 29,8 \\
\hline
\end{tabular}

Hi-square test certified statistically significant dependency between sort of surgical treatment and days spent at the intensive care $\left(\chi_{2}=17 ; p=0\right)$.

Table 3. Dependency between sort of surgical treatment and days spent and the standard care ward

\begin{tabular}{|c|c|c|c|c|}
\hline \multirow{2}{*}{$\begin{array}{l}\text { Sorg of } \\
\text { surgical } \\
\text { treatment }\end{array}$} & \multirow{2}{*}{ Relation (N) } & \multicolumn{2}{|c|}{$\begin{array}{l}\text { Day of standard } \\
\text { care (DSC) }\end{array}$} & \multirow{2}{*}{ - Total } \\
\hline & & $\begin{array}{l}\text { Less } \\
\text { than } 9\end{array}$ & $\begin{array}{l}\text { More } \\
\text { than } 9 \\
\end{array}$ & \\
\hline \multirow{4}{*}{ Pulmoctomy } & $\mathrm{N}$ & 7 & 12 & 19 \\
\hline & Sort of surgical tr. & 36,8 & 63,2 & 100 \\
\hline & DIC & 18,4 & 63,2 & 33,3 \\
\hline & Total & 12,3 & 21,1 & 33,3 \\
\hline \multirow{4}{*}{$\begin{array}{l}\text { Pulmoctomy } \\
\text { with } \\
\text { preservation } \\
\text { of bronchus }\end{array}$} & $\mathrm{N}$ & 17 & 4 & 21 \\
\hline & Sort of surgical tr. & 81,0 & 19,0 & 100 \\
\hline & DIC & 44,8 & 21,1 & 36,8 \\
\hline & Total & 29,8 & 7,1 & 36,8 \\
\hline \multirow{4}{*}{$\begin{array}{l}\text { Lobectomy } \\
\text { Bilobectomy }\end{array}$} & $\mathrm{N}$ & 14 & 3 & 17 \\
\hline & Sort of surgical tr. & 82,4 & 17,6 & 100 \\
\hline & $\mathrm{DIC}$ & 36,8 & 15,9 & 29,8 \\
\hline & Total & 24,6 & 5,3 & 29,8 \\
\hline
\end{tabular}


Chi-square test certified statistically significant dependency between sort of surgical treatment and days spent at the standard care ward $\left(\chi_{2}=11 ; p=0\right)$.

Table 4. numerically shows post operational complications which appeared during hospital treatment at patients who underwent inductive oncological therapy

Table 4. Relationship between number of early complications in relation to sort of operation

\begin{tabular}{|c|c|c|c|c|}
\hline $\begin{array}{l}\text { Sort of } \\
\text { complication }\end{array}$ & $\begin{array}{l}\text { Pulmectomy } \\
\text { with } \\
\text { preservation } \\
\text { of bronchus }\end{array}$ & $\begin{array}{l}\text { Pulmec- } \\
\text { tomy }\end{array}$ & $\begin{array}{l}\text { Bilobec- } \\
\text { tomy } \\
\text { Lobec- } \\
\text { tomy }\end{array}$ & $\begin{array}{l}\text { Eksplora- } \\
\text { tive } \\
\text { thoraco- } \\
\text { tomy }\end{array}$ \\
\hline Cardiovascular & 5 & 4 & 2 & 0 \\
\hline Pulmlogical & 3 & 2 & 1 & 1 \\
\hline Fistula BP & 0 & 3 & 0 & 0 \\
\hline Empyiema pl. & 0 & 1 & 0 & 0 \\
\hline Chemoragy & 1 & 2 & 1 & 0 \\
\hline $\begin{array}{l}\text { Infection of } \\
\text { wound }\end{array}$ & 1 & 1 & 1 & 0 \\
\hline Death & 0 & 2 & 0 & 0 \\
\hline Without compl. & 9 & 8 & 12 & 4 \\
\hline Total & 19 & 21 & 17 & 5 \\
\hline
\end{tabular}

\section{Discussion}

In our analysis, relation between getting a disease in relation to gender which is 3:1 in advance of males responds to modern data, while the reason for this is more frequent use of consuming nicotine which is more common with male gender. Appearance of disease at elderly population where the average age of total number of surgically treated patients is $62 \pm 1$ (male $63 \pm 1$; female $57 \pm 3$ ), confirms time flow of disease until the appearance of symptoms. ${ }^{4,5,12,13}$

Abundance of disc layer cancer at male was 80\% adenocancer $15 \%$ and macro cellular malign $5 \%$. At female gender this percentage relation between the two most common types of cancer was 50\%:50\%. Mentioned data correspond to available data which describe this field. ${ }^{3-5,14}$ There was a statistical significance of appearance of the two most common types of cancer at total number of patients $(\mathrm{p}=0)$, as well as relation to gender $(\mathrm{p}=0)$.

Regression of size change in average of $27 \pm 2$ millimeters $(78 \pm 3 \mathrm{~mm}$. v.s. $51 \pm 3 \mathrm{~mm}$.) in our work is statistically significant $(p<0,05)$. In our work, there was no statistical dependence between sort of cancer and its sensitivity to chemotherapy $(\mathrm{p}=0,2)$, the same as there was no statistical dependence of chemotherapy sensitivity in relation to gender $(\mathrm{p}=1)$. According to present oncological data adenocancer has better chemotherapy response. ${ }^{3,6,7}$
Taking into account the expected post operational complications, was the greatest number of pulmectomies with preservation of bronchus by trans positioned stem of inter costal muscle (34\%) muscle was performed $31 \%$ of standard pulmectomy, lobectomy and bilebectomy $27 \%$, while $8 \%$ of patients underwent explorative thoratocomy were performed as well. At resectabilable cases regional regional lymph denectomy was done. Percent relation of sort of surgical treatment of our analysis was identical to the available data from the mentioned field. ${ }^{2,10,15}$ In our work, there was no statistically significant difference in frequency of type of surgical treatment in relation to type of cancer $\left(x^{2}=1 ; p=0,6\right)$.

Average number of days spent at intensive care was 6,8 $\pm 0,4$. Much greater number of patients who underwent plumoctomy with preservation of bronchus spent less then the mentioned average $-48 \%$ in relation to other group who underwent plumoctomy -26\%. 94\% of patients who went through lobectomy treatment spent less time at intensive care than mentioned in average (Table.2). From the abovementioned, the significance the significance of sort and technic of surgical treatment and time spent at intensive care $\left(\chi^{2}=17 ; p=0\right)$ is seen. Significant statistical dependence between gender of patients and type of cancer and days spent at intensive care was not found. There is confirmed statistically significant dependency between response to CT and days spent at intensive care $(\mathrm{p}=0,03)$.

Average number of days spent at hospital ward was $8,5 \pm 1.81 \%$ of those who underwent pulmoctomy with preservation of bronchus spent less number of days in relation to the rest of those who underwent pulmoctomy $-37 \%$. Patients who underwent lobectomy spent less than the mentioned number of days at ward (Tab.3). Relation between sort of surgical treatment and time spent at ward was statistically significant $(\chi 2=1 ; p=0)$.

There was no evidence of significant dependency between gender of patients, type of cancer, impact of chemotherapy and days spent at the hospital standard care ward.

Statistically positive connection between days spent at intensive care and days spent at the ward at surgically treated patients with lung cancer $(\mathrm{rho}=0.62 ; \mathrm{p}<0.01)$ was confirmed. Duration of postsurgical flow of our patients was identical to the number of days in comparison to available studies..$^{2,3,10,11,16}$

In Table 4, there is numerically shown number of complication at analyzed cases which appeared during the treatment in hospital. Cardiopulmonal complications ware most commonly followed by disorder of heart rhythm and tension, which at two patients were possibly the cause of death. At two patients, there was also appearance of bronchus pleural fistula and those were the patients that didn't undergo the preservation of bronchus. Postsurgical bleeding from the wall of 